\title{
Cervical spinal cord compression in a patient with Trisomy 21
}

\author{
Michale Ok, MD · Usha Nagaraj, MD • Mohamed Mahmoud, MD
}

Received: 8 March 2019/Revised: 3 April 2019/Accepted: 3 April 2019/Published online: 15 April 2019

(C) Canadian Anesthesiologists' Society 2019

A six-year-old male patient with Trisomy 21 presented for C1 laminectomy and posterior occipito-cervical fusion because of worsening lower extremity weakness and generalized hypotonia. Sagittal magnetic resonance imaging (MRI) of the cranio-cervical junction (Panel A) showed widening of the atlanto-axial interval (white dotted line), thickening of the transverse ligament (white arrow), and hypoplasia of the $\mathrm{C} 1$ vertebral ring (black arrow). This combination resulted in an anteriorly displaced posterior $\mathrm{C} 1$ arch in relation to the opisthion (dorsal border of the foramen magnum) with subsequent narrowing of the spinal canal and cervical cord compression (black dotted line). The axial MRI (Panel B) showed flattening of the spinal cord (white arrows). Motor and somatosensory evoked potential monitoring after flexible bronchoscopic intubation and positioning did not reveal any significant changes compared to baseline signals.

Preexisting narrowing of the spinal canal is particularly concerning for patients with Trisomy 21 because it results in less room for dorsal movement of the odontoid process, which, in turn, could amplify the risk of spinal cord damage following atlanto-axial subluxation. ${ }^{1}$ Awareness and understanding of the significant risk of neurologic injury with excessive movement of the neck in these patients is imperative. A thorough history and physical examination should be conducted to look for signs or symptoms suggestive of cord compression before ordering cervical spine imaging. Routine cervical imaging is not recommended for asymptomatic children with Trisomy 21 because abnormal atlanto-axial intervals on radiographs do not necessarily indicate that the patient is at risk of neurologic injury. ${ }^{2}$

Precautions to maintain the neck in neutral position during airway manipulation is recommended. Flexible bronchoscopic intubation or in-line stabilization of the neck may help protect the cervical spine. ${ }^{3}$ Motor and somatosensory evoked potential monitoring during intubation and neck manipulation is another important consideration when these patients with cervical instability undergo procedures requiring significant neck manipulation. ${ }^{4}$ Because motor evoked potentials detect injury to the anterior spinal cord and somatosensory evoked potentials are useful for monitoring the posterior cord, the two modalities in combination provide comprehensive monitoring of the spinal cord under anesthesia. For surgery requiring intraoperative neuromonitoring, it may be reasonable to obtain baseline evoked potential recordings before intubation to determine if there are any signal abnormalities prior to neck manipulation as well as after intubation and positioning the patient to confirm the absence of pathologic changes from the baseline results. 
Figure Panel A) Sagittal magnetic resonance imaging (MRI) of the cranio-cervical junction shows widening of the atlanto-axial interval (white dotted line), thickening of the transverse ligament (white arrow), and hypoplasia of the $\mathrm{C} 1$ ring (black arrow). This combination results in spinal canal stenosis and cervical cord compression (black dotted line). Panel B) The axial MRI shows flattening of the spinal cord (white arrows)

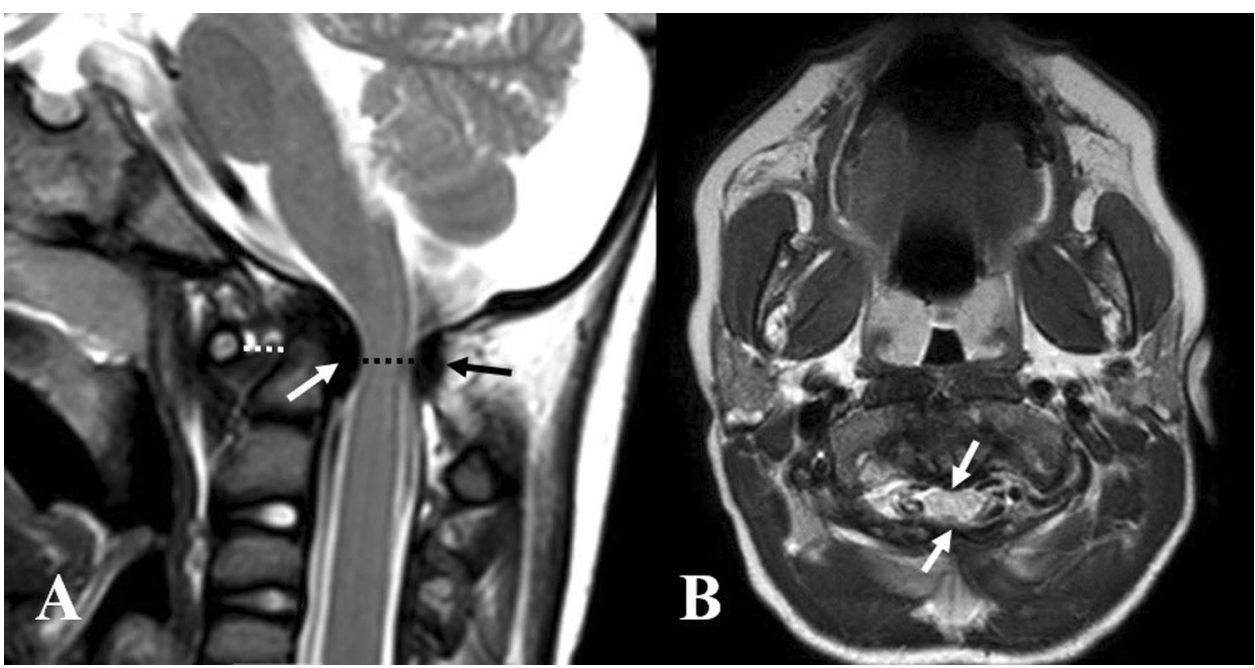

Competing interests None declared.

Editorial responsibility This submission was handled by Dr. Hilary P. Grocott, Editor-in-Chief, Canadian Journal of Anesthesia.

Funding sources Departmental salary; no external sources.

\section{References}

1. Martich V, Ben-Ami T, Yousefzadeh DK, Roizen NJ. Hypoplastic posterior arch of $\mathrm{C}-1$ in children with Down syndrome: a double jeopardy. Radiology 1992; 183: 125-8.
2. Cohen WI. Current dilemmas in Down syndrome clinical care: celiac disease, thyroid disorders, and atlanto-axial instability. Am J Med Genet C Semin Med Genet 2006; 142C: 141-8.

3. Lewanda AF, Matisoff A, Revenis $M$, et al. Preoperative evaluation and comprehensive risk assessment for children with Down syndrome. Paediatr Anaesth 2016; 26: 356-62.

4. Al Bahri RS, MacDonald DB, Mahmoud AH. Motor and somatosensory evoked potential spinal cord monitoring during intubation and neck extension for thyroidectomy in a Down syndrome boy with atlantoaxial instability. J Clin Monit Comput 2017; 31: 231-3.

Publisher's Note Springer Nature remains neutral with regard to jurisdictional claims in published maps and institutional affiliations. 